\title{
Low Expression of miR-126 Is a Prognostic Marker for Metastatic Clear Cell Renal Cell Carcinoma
}

Heba W.Z. Khella, ${ }^{* \dagger \ddagger}$ Andreas Scorilas, ${ }^{\S}$ Roy Mozes, ${ }^{*}$ Lorna Mirham, ${ }^{\ddagger}$ Evi Lianidou, ${ }^{\llbracket}$ Sergey N. Krylov,, Jason Y. Lee, ${ }^{* *}$ Michael Ordon, ${ }^{* *}$ Robert Stewart, ${ }^{* *}$ Michael A.S. Jewett, ${ }^{\dagger \dagger}$ and George M. Yousef ${ }^{* \dagger \dagger}$

From the Department of Laboratory Medicine and the Keenan Research Centre for Biomedical Science of the Li Ka Shing Knowledge Institute* and the Division of Urology, ** St. Michael's Hospital, Toronto, Ontario, Canada; the Institute of Medical Science ${ }^{\dagger}$ and the Department of Laboratory Medicine and Pathobiology, ${ }^{\ddagger}$ University of Toronto, Toronto, Ontario, Canada; the Departments of Biochemistry and Molecular Biology $y^{\S}$ and Chemistry, ${ }^{\Uparrow}$ University of Athens, Athens, Greece; the Department of Chemistry and Centre for Research on Biomolecular Interactions, "York University, Toronto, Ontario, Canada; and the Division of Urologic Oncology ${ }^{\dagger \dagger}$ Department of Surgery, Princess Margaret Cancer Center, University Health Network, Toronto, Ontario, Canada

Accepted for publication

November 13, 2014.

Address correspondence to George M. Yousef, M.D., Ph.D., Department of Laboratory Medicine, St. Michael's Hospital, 30 Bond St., Toronto, ON M5B 1W8, Canada. E-mail: yousefg@smh.ca.

\begin{abstract}
Clear cell renal cell carcinoma (ccRCC) is an aggressive tumor with unpredictable behavior. Clinical parameters are not always accurate for predicting prognosis. miR-126 is differentially expressed in many cancers, including RCC, and is down-regulated in metastatic versus primary ccRCC. We assessed the prognostic significance of miR-126 in 264 primary ccRCCs. We also compared its expression in normal kidney, primary and metastatic CCRCC, and RCC subtypes. We validated our results on an independent set of 481 ccRCCs. miR-126 was down-regulated in metastatic versus primary tumors and in tumors of higher stage $(P=0.005)$ or higher grade $(P=0.002)$. miR-126 up-regulation was associated with significantly prolonged disease-free survival $(P<0.001)$ and overall survival $(P=0.015)$. For larger tumors $(>4 \mathrm{~cm})$, patients with higher miR-126 expression had significantly longer survival. Restoration of miR-126 expression decreased cellular migration and proliferation in RCC cell lines. The cCRCCs exhibited the highest miR-126 expression, and papillary RCCs exhibited the lowest expression. We identified a number of miR-126 targets and pathways that are involved in carcinogenesis, including the apoptosis signaling pathway. miR-126 is a promising prognostic marker in cCRCC that can distinguish between clear cell and papillary subtypes. In addition, miR-126 has potential therapeutic applications. (Am J Pathol 2015, 185: 693-703; http://dx.doi.org/10.1016/j.ajpath.2014.11.017)
\end{abstract}

Renal cell carcinoma (RCC) is the most common form of kidney cancer in adults. Recent reports show its increased incidence worldwide and marked increase of years of life lost due to kidney cancer in the past two decades. ${ }^{1,2}$ From $20 \%$ to $30 \%$ of RCC patients have metastatic disease at the time of diagnosis, and $20 \%$ to $40 \%$ develop metastasis later, after nephrectomy. ${ }^{3}$

The known RCC subtypes include clear cell RCC (ccRCC), papillary RCC, and chromophobe RCC. ccRCC is both the most common of these subtypes, accounting for $75 \%$ to $80 \%$ of cases, and the most aggressive. ${ }^{3-5}$

The currently used staging system, which is based on clinicopathological parameters, lacks accuracy in predicting the natural outcome of the disease, especially in nonmetastatic RCC. ${ }^{6}$ Also, given the availability of advanced imaging techniques, many RCC cases are diagnosed in an early, asymptomatic stage. Patients are usually in stage I and with small renal mass (ie, $\leq 4 \mathrm{~cm}$ maximum diameter). The prognosis is unpredictable, because these small renal masses can be either progressive or nonprogressive. ${ }^{7}$ Although larger tumors are generally associated with worse prognosis, tumor size alone is not an accurate prognostic predictor in RCC., There is urgent need for molecular biomarkers that can help accurately predict disease outcome. Such biomarkers, used alone or in combination with other clinical parameters, could significantly improve patient management.

miRNAs are short noncoding RNAs that regulate gene expression by binding to the $3^{\prime}$-UTR of their target genes.

Supported by Canadian Institutes of Health Research grant MOP 119606 Kidney Foundation of Canada grant KFOC130030, the Kidney Cancer Research Network of Canada, and the Prostate Cancer Canada Movember Discovery grant D2013-39 (all to G.M.Y.).

Disclosures: None declared. 
miRNAs are involved in a variety of biological functions, including cellular proliferation, differentiation, and apoptosis, which points to a role of miRNAs in tumor development and progression in different cancers. ${ }^{10,11}$ miRNAs have also been shown to be potential prognostic markers in RCC. ${ }^{12-14}$

In previous work, we identified a miRNA signature associated with metastatic RCC and provided preliminary evidence that these small molecules are promising prognostic biomarkers in kidney cancer. miR-126 was one of the significantly down-regulated miRNAs in metastatic versus primary ccRCC. ${ }^{15,16}$

miR-126 is an intronic miRNA, located in intron 7 of the epidermal growth factor-like protein 7 gene (EGFL7) on chromosome 9. In mouse, Egfl7 T-2 promoter epigenetic changes are correlated with miR-126 expression in breast cancer progression. ${ }^{17}$ miR-126 differential expression has been reported in various cancers, including colorectal, prostate, lung, gastric, esophageal, and breast cancers. ${ }^{18-22}$

miR-126 has also been shown to have a tumor suppressor effect in melanoma. ${ }^{23}$ miR-126 is expressed in endothelial cells and controls angiogenesis in cancer. ${ }^{24-26}$ In mice, it regulates a proangiogenic gene, $K d r$, which encodes vascular endothelial growth factor receptor 2 (VEGFR2). ${ }^{24}$ miR-126 was also shown to decrease cellular migration and invasion in colorectal cancer by targeting CXCR $4,{ }^{27} \mathrm{RhoA} / \mathrm{ROCK},{ }^{28}$ VCAM-1, and the PI3K/Akt signaling pathway. ${ }^{29}$ miR-126 decreases cellular proliferation in osteosarcoma. ${ }^{30}$

In the present study, we examined the clinical utility of miR126 as a prognostic marker in RCC. We correlated the expression of miR-126 with various clinical parameters and survival data. We validated our results on another independent set of patients from The Cancer Genome Atlas (TCGA). We also tested the ability of miR-126 to predict disease progression in subgroups of patients with stage I RCC (tumor size $\leq 4$ $\mathrm{cm}$ versus $>4 \mathrm{~cm}$ ) and tested the effect of miR-126 overexpression on cellular migration and proliferation in RCC cellline models. We identified miR-126-predicted targets and pathways and tested the effect of restoration of miR-126 expression level on apoptosis signaling pathway. Finally, we compared miR-126 among subtypes of RCC.

\section{Materials and Methods}

\section{Specimen Collection}

We examined expression of miR-126 in 264 primary ccRCC and 20 metastatic ccRCC formalin-fixed, paraffin-embedded tissues. Specimens were collected from St. Michael's Hospital and University Health Network, Toronto, ON, Canada. Areas of pure tumor tissue with no hemorrhage or necrosis were selected by a pathologist (L.M. or G.M.Y.). Multiple sections were mixed from the same tumor, to compensate for tumor heterogeneity. Pure tumor areas were excised using lasercapture microdissection. Tumor classification and staging were according to the 2002 TNM system and the 2004 World Health Organization Classification of Tumours. ${ }^{31}$
Distribution of the numerical variables of the study is shown in Supplemental Table S1. All procedures were approved by the Research Ethics Board at St. Michael's Hospital and University Health Network. RNA was extracted from 40 pairs of normal and cancer fresh tissues from the same patient, for comparison of miR-126 expression in the paired tissues. We also compared expression of miR-126 in normal kidney, oncocytoma, and RCC subtypes using fresh tissues obtained from 20 samples for each group. Fresh specimens were collected immediately after resection, snap-frozen in liquid nitrogen, and stored at $-80^{\circ} \mathrm{C}$ until total RNA extraction.

\section{Total RNA Extraction}

Total RNA was isolated using an miRNeasy kit (Qiagen, Mississauga, ON, Canada; Valencia, CA) according to the manufacturer's protocol and as described previously. ${ }^{15}$ RNA quality and concentration were determined spectrophotometrically (NanoDrop 1000 spectrophotometer; Thermo Fisher Scientific, Waltham, MA). Samples optimal for analysis were stored at $-80^{\circ} \mathrm{C}$.

\section{RT-qPCR}

For real-time quantitative RT-PCR (RT-qPCR), miR126-specific reverse transcription was performed with $5 \mathrm{ng}$ total RNA using a TaqMan microRNA reverse transcription kit (Life Technologies, Carlsbad, CA) as described by the manufacturer for miR-126.

RT-qPCR was performed using a TaqMan microRNA assay kit on a Step One Plus real-time PCR system (Life Technologies). Thermal cycling conditions were as specified by the manufacturer's fast protocol, and all reactions were performed in triplicate. Relative expression was determined using the $\Delta \Delta \mathrm{C}_{\mathrm{T}}$ method, and expression values were normalized to small nucleolar RNAs RNU48 and RNU44 (Life Technologies).

\section{Statistical Analysis}

Gene expression analysis was performed using the comparative $\mathrm{C}_{\mathrm{T}}$ method. Expression levels were normalized to the geometrical mean of two reference genes, SNORD44 (RNU44) and SNORD48 (RNU48).

Because miR-126 expression levels do not exhibit Gaussian distribution, we performed $U$ testing to examine differences in miR-126 expression status between primary and metastatic tumors. Correlations between continuous variables of the study (ie, miR-126 expression levels and tumor size) were assessed by Spearman's correlation coefficient. The relation of miR-126 expression levels as a continuous variable with many clinicopathological parameters, nominal and ordinal, was examined by $U$ test and Jonckheere-Terpstra test, respectively. Converting a continuous variable to a dichotomous one is often helpful (eg, for classifying a patient cohort into high and low categories). Using the X-tile algorithm, which produces an 
optimal cutpoint and corrects for use of minimum $P$-value statistics, we established a cutoff point of 2.15 relative quantification units (equivalent to the 20th percentile) and we classified the patients into two groups, miR- $126^{+}$and miR$126^{-}$. Using either Fisher's exact test or Pearson's $\chi^{2}$ test, we evaluated associations between miR-126 status and various clinicopathological variables. Survival analysis and appraisal of the prognostic value of miR-126 was performed not only by developing univariate and multivariate Cox proportional hazard regression models, but also by constructing Kaplan-Meier disease-free survival (DFS) and overall survival (OS) curves. DFS was defined as the time between the initial resection of the kidney tumor and the event of recurrence or metastasis. OS was defined as the time between the initial resection of the kidney tumor and the date of death or date of last contact.

The multivariate model was adjusted for patient age, histological stage, and tumor grade, and $P$ values were calculated by the test for trend approach. $P<0.05$ was considered indicative of statistical significance.

\section{Cell Culture and miRNA Transfection}

The RCC cell lines 786-O and ACHN were obtained from ATCC (Manassas, VA) and were grown according to the manufacturer's protocol. Pre-miR miRNA precursor for miR126 was purchased from Life Technologies. Cells were transfected using Ambion siPORT NeoFX transfection agent (Life Technologies) as recommended by the manufacturer and as described previously. ${ }^{32,33}$ The transfection agent was diluted in Opti-MEM reduced serum medium (Life Technologies) and incubated for 10 minutes at room temperature. miR-126 precursor was diluted in the same medium to a final concentration of $30 \mathrm{nmol} / \mathrm{L}$, combined with the transfection agent, and incubated for 10 minutes at room temperature. Transfection mixtures were added to the cell-culture plate and overlaid with cell suspensions. Cells were incubated at $37^{\circ} \mathrm{C}$ and $5 \% \mathrm{CO}_{2}$. Three separate transfections were performed, and each was analyzed in triplicate. Transfection efficiency was confirmed using BLOCK-iT Fluorescent Oligo oligomer (Life Technologies).

\section{Migration Assay}

786-O cells were seeded in a 12-well plate, and transfected with siPORT NeoFX transfection agent, negative control, or miR-126. At 24 hours after transfection, the cell monolayer was wounded using a $200-\mu \mathrm{L}$ pipette tip. Hydroxyurea (100 $\mathrm{mmol} / \mathrm{L}$ ) was added to the cell culture to inhibit cell proliferation. Photomicrographs were taken every 30 minutes starting at the time of wounding ( 0 hour) and ending at 9 hours. ImageJ software version $1.47 \mathrm{v}$ (NIH, Bethesda, MD) was used for cell migration analysis. Percent cell-free area was calculated as (cell-free area $_{9 \text { hours }} /$ cell-free area $\left.a_{0 \text { hours }}\right) \times$ 100 , and cell migration rate was expressed as a percentage of the cell-covered area (ie, as 100 - percent cell-free area). Each experiment was performed in triplicate.

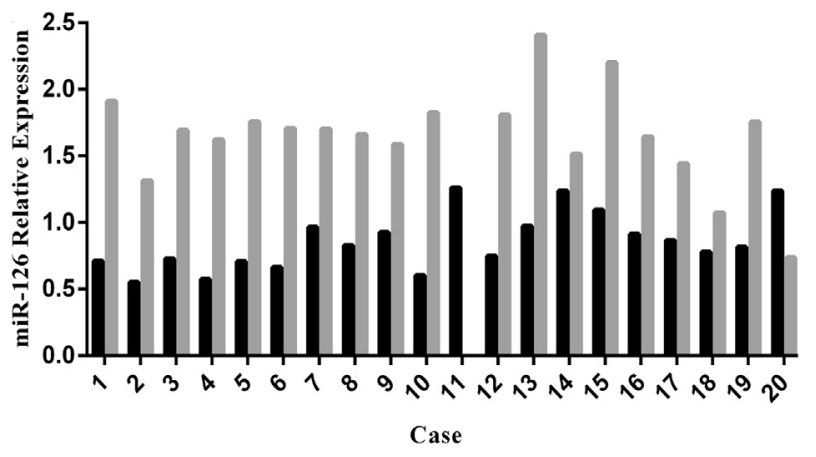

Figure 1 miR-126 is up-regulated in ccRCC versus normal kidney. miR126 expression in paired normal kidney and ccRCC specimens from 20 representative patients. ccRCC, clear cell renal cell carcinoma.

\section{Cell Proliferation Assay}

Cellular proliferation was measured by using a cell proliferation reagent WST-1 (Roche Applied Science, Indianapolis, IN) colorimetric assay. Cells were plated at $6.0 \times 10^{3}$ cells per well in a 96-well plate and transfected with siPORT NeoFX transfection agent, negative control, or miR-126. The cell proliferation reagent WST-1 was added to each well, and cells were incubated for 2 hours at $37^{\circ} \mathrm{C}$. The absorbance of each well was measured at a wavelength of $440 \mathrm{~nm}$. Each test was repeated in six replicates.

\section{Clinical Validation on a TCGA Data Set}

We compiled miR-126 read counts and clinical variables associated with ccRCC patients from TCGA (https://tcgadata.nci.nih.gov/tcga/tcgaHome2.jsp, last accessed November $7,2014)$. Clinical variables that were analyzed in relation to miR-126 read counts included OS time, pathological stage, and tumor size in 481 patients. Read counts of miR-126 were compared in 68 matched pairs of ccRCC and normal kidney tissues. Data were obtained from TCGA. We also obtained the expression levels of a number of miR-126-predicted targets (including PIK3CD, PIK3R2, and VEGFA) in 481 ccRCCs, and we correlated the expression levels of these targets with OS. Cutoff points were determined, and Kaplan-Meier curves were constructed using Cutoff Finder software (http://molpath. charite.de/cutofflindex.jsp, last accessed November 7, 2014).

\section{Bioinformatic Analysis}

\section{Target Prediction and Pathway Analysis}

Target prediction was performed using TargetScanHuman software release 6.2 (http://www.targetscan.org, last accessed November 7, 2014). We also used miRecords ${ }^{34}$ software that combines the results of 11 prediction programs; only predictions made by at least three programs were included. We filtered the predicted gene targets list through extensive literature search and pathway analysis using DIANA-miRPath software version 2.0 (http://diana.imis.athena-innovation.gr/DianaTools/index. $p h p ? r=$ mirpath/index last accessed November 7, 2014) and 
Table 1 miR-126 Expression As a Continuous Variable Stratified According to Classical Clinicopathological Parameters

miR-126 expression

(RQ units)

\begin{tabular}{|c|c|c|c|c|}
\hline \multirow[b]{2}{*}{ Variable } & \multirow[b]{2}{*}{ No. of patients } & & \multirow[b]{2}{*}{$P$ value } \\
\hline & & Means \pm SEM & Median & \\
\hline \multicolumn{5}{|l|}{ Age (years) } \\
\hline$\leq 61$ & 130 & $11.10 \pm 1.26$ & 6.56 & \multirow[t]{2}{*}{0.839} \\
\hline$>61$ & 130 & $13.82 \pm 1.98$ & 6.25 & \\
\hline \multicolumn{5}{|l|}{ Sex } \\
\hline Male & 171 & $12.66 \pm 1.34$ & 6.71 & \multirow[t]{2}{*}{0.621} \\
\hline Female & 91 & $11.94 \pm 2.25$ & 5.94 & \\
\hline \multicolumn{5}{|l|}{ Tumor status } \\
\hline Primary & 264 & $12.41 \pm 1.17$ & 6.51 & \multirow[t]{2}{*}{0.827} \\
\hline Metastatic & 20 & $10.45 \pm 3.10$ & 6.95 & \\
\hline \multicolumn{5}{|c|}{ Tumor size $(\mathrm{cm})$} \\
\hline$\leq 4.0$ & 88 & $15.46 \pm 3.16$ & 6.96 & \multirow[t]{2}{*}{0.069} \\
\hline$>4.0$ & 171 & $12.52 \pm 1.75$ & 5.47 & \\
\hline \multicolumn{5}{|l|}{ Laterality } \\
\hline Left & 142 & $14.32 \pm 1.87$ & 6.84 & \multirow[t]{2}{*}{0.185} \\
\hline Right & 118 & $10.11 \pm 1.18$ & 6.16 & \\
\hline \multicolumn{5}{|l|}{ Tumor stage } \\
\hline I/II & 167 & $13.22 \pm 1.48$ & 6.78 & \multirow[t]{2}{*}{0.012} \\
\hline III/IV & 90 & $11.18 \pm 1.99$ & 5.23 & \\
\hline \multicolumn{5}{|l|}{ Tumor grade } \\
\hline I/II & 121 & $12.12 \pm 1.29$ & 7.23 & \multirow[t]{2}{*}{0.016} \\
\hline III/IV & 134 & $12.93 \pm 1.97$ & 5.82 & \\
\hline
\end{tabular}

$P$ values were calculated by Mann-Whitney $U$ test.

$R Q$, relative quantification.

the Gene Functional Classification tool from the DAVID Bioinformatics Database version 6.7 (http://david.abcc.ncifcrf.gov/ gene2gene.jsp, last accessed November 7, 2014).

\section{Phylogenetic Analysis}

The University of California Santa Cruz Genome Browser (http://genome.ucsc.edu/cgi-bin/hgGateway, last accessed November 24, 2013) was used for sequence comparison of miR-126. Conservation among species of these miRNAs was examined with sequence alignment in the genomes of 46 vertebrate species.

\section{TaqMan Array Human Gene Expression Assays}

We tested the effect of miR-126 overexpression on apoptosis by TaqMan array human gene expression assays using a StepOnePlus real-time PCR system (Life Technologies). 786-O cells transfected with miR-126 were compared with untransfected cells. Total RNA was isolated using an RNeasy mini kit (Qiagen) according to the manufacturer's protocol. Reverse transcription was performed using a high-capacity cDNA reverse transcription kit (Life Technologies). This was followed by PCR amplification using TaqMan Array human gene expression assays specific for human apoptosis. Fold change was calculated by the $2^{-\Delta \Delta C t}$ method. First, $\Delta C_{T}$ values were calculated for each target by normalizing its threshold cycle to the average of four endogenous controls including 18S,
$G A P D H, H P R T 1$, and GUSB. Then, $\Delta \Delta \mathrm{C}_{\mathrm{T}}$ was calculated as 786- $\mathrm{O}_{\text {miR-126 transfected }}$ cells $-786-\mathrm{O}_{\text {untransfected }}$ cells $\times \Delta \mathrm{C}_{\mathrm{T}}$.

\section{Results}

miR-126 Is Overexpressed in ccRCC versus Normal Kidney

We used RT-qPCR analysis to compare miR-126 expression in 40 pairs of normal kidney and ccRCC tissues from the same patient. miR-126 was up-regulated in ccRCC, compared with normal tissue counterparts (Figure 1). We validated our results on 68 pairs of normal kidney and ccRCC tissues using data from TCGA, which confirmed the up-regulation of miR-126 in cancer $(P<0.0001)$ (Supplemental Figure S1, A and B).

\section{miR-126 Is Down-Regulated in Metastatic versus Primary $\mathrm{ccRCC}$}

We assessed miR-126 expression in 264 primary and 20 metastatic ccRCC tumors by RT-qPCR. miR-126 expression was decreased in metastatic versus primary ccRCC $(10.45 \pm 3.10$ versus $12.47 \pm 1.17$, mean $\pm \mathrm{SEM})$, although the difference was not statistically significant $(P=0.827)$ (Table 1).

Table 2 Associations between miR-126 Status As a Binary Variable and Clinicopathological Parameters

\begin{tabular}{|c|c|c|c|c|}
\hline \multirow[b]{2}{*}{ Variable } & \multicolumn{3}{|c|}{ No. of patients (\%) } & \multirow[b]{2}{*}{$P$ value } \\
\hline & Total & $\operatorname{miR}-126^{-}$ & $\operatorname{miR}-126^{+}$ & \\
\hline \multicolumn{5}{|c|}{ Age (years) } \\
\hline$\leq 61$ & 130 & $25(19.2)$ & $105(80.8)$ & \multirow[t]{2}{*}{$1.000 *$} \\
\hline$>61$ & 130 & $25(19.2)$ & $105(80.8)$ & \\
\hline \multicolumn{5}{|l|}{ Sex } \\
\hline Male & 171 & $32(18.7)$ & $139(81.3)$ & \multirow[t]{2}{*}{$0.5^{*}$} \\
\hline Female & 91 & $20(22.0)$ & $71(78.0)$ & \\
\hline \multicolumn{5}{|l|}{ Laterality } \\
\hline Left & 142 & $25(17.6)$ & $117(82.4)$ & \multirow[t]{2}{*}{$0.528^{*}$} \\
\hline Right & 118 & $25(21.2)$ & $93(78.8)$ & \\
\hline \multicolumn{5}{|c|}{ Tumor size $(\mathrm{cm})$} \\
\hline$\leq 4.0$ & 88 & $11(12.5)$ & $77(87.5)$ & \multirow[t]{2}{*}{$0.048^{*}$} \\
\hline$>4.0$ & 171 & $39(22.8)$ & $132(77.2)$ & \\
\hline \multicolumn{5}{|c|}{ Tumor stage } \\
\hline I & 126 & $16(12.7)$ & $110(87.3)$ & \multirow[t]{4}{*}{$<0.001^{\dagger}$} \\
\hline II & 41 & $7(17.1)$ & $34(82.9)$ & \\
\hline III & 81 & $20(24.7)$ & $61(75.3)$ & \\
\hline IV & 9 & $7(77.8)$ & $2(22.2)$ & \\
\hline \multicolumn{5}{|c|}{ Tumor grade } \\
\hline $\mathrm{I}$ & 15 & $2(13.3)$ & $13(86.7)$ & \multirow[t]{4}{*}{$0.002^{\dagger}$} \\
\hline II & 106 & $13(12.3)$ & $93(87.7)$ & \\
\hline III & 100 & $18(18.0)$ & $82(82.0)$ & \\
\hline IV & 34 & $14(41.2)$ & $20(58.8)$ & \\
\hline
\end{tabular}

Cutoff point: 2.15 relative quantification units (equivalent to the 20th percentile). Relative quantification to the geometrical mean of two reference genes RNU44 and RNU48.

*Fisher's exact test.

†Pearson's $\chi^{2}$ test. 
Table 3 miR-126 Expression and Patient Survival

\begin{tabular}{|c|c|c|c|c|c|c|}
\hline \multirow[b]{2}{*}{ Variable } & \multicolumn{3}{|c|}{ Disease-free survival } & \multicolumn{3}{|c|}{ Overall survival } \\
\hline & $H R^{*}$ & $95 \% \mathrm{CI}^{\dagger}$ & $P$ value & $H R^{*}$ & $95 \% \mathrm{CI}^{\dagger}$ & $P$ value \\
\hline \multicolumn{7}{|l|}{$\begin{array}{l}\text { Univariate analysis } \\
\text { miR-126 }\end{array}$} \\
\hline- & 1.00 & & & 1.00 & & \\
\hline+ & 0.30 & $0.18-0.50$ & $<0.001$ & 0.40 & $0.19-0.86$ & 0.019 \\
\hline Age & 1.01 & $0.99-1.03$ & 0.34 & 0.99 & $0.97-1.02$ & 0.84 \\
\hline \multicolumn{7}{|l|}{$\begin{array}{l}\text { Multivariate analysis } \\
\text { miR-126 }\end{array}$} \\
\hline- & 1.00 & & & 1.00 & & \\
\hline+ & 0.58 & $0.32-1.04$ & 0.066 & 0.78 & $0.32-1.87$ & 0.57 \\
\hline Age & 1.00 & $0.98-1.02$ & 0.89 & 0.98 & $0.95-1.02$ & 0.31 \\
\hline
\end{tabular}

*Hazard ratio, estimated from Cox proportional hazard regression model.

${ }^{\dagger}$ Confidence interval of the estimated HR.

${ }_{\ddagger}^{\ddagger}$ Multivariate models were adjusted for patient age, histological stage, and tumor grade.

\section{miR-126 Is a Potential Prognostic Marker for RCC}

miR-126 Expression Level and Its Association with Clinicopathological Characteristics

We tested the association between miR-126 expression and the different clinicopathological characteristics in 264 primary ccRCC cases. As a continuous variable, miR-126 was significantly down-regulated in tumor stages III/IV compared with stages $\mathrm{I} / \mathrm{II}(P=0.012)$. Also, miR-126 expression was significantly lower in tumor grade III/IV, compared with grade $\mathrm{I} / \mathrm{II}(P=0.016)$. There was no significant association between miR-126 expression level and age, sex, tumor size, or laterality (Table 1).

As a binary variable, miR-126 overexpression negatively correlated with tumor size; miR-126 positivity was observed in $88 \%$ of cases with smaller tumors $(\leq 4 \mathrm{~cm})$, compared with $77 \%$ of cases with larger tumors $(>4 \mathrm{~cm})(P=0.048)$ (Table 2). Furthermore, there was a stepwise decrease of miR-126 positivity with increasing tumor stage $(P<0.001)$. The percentage of cases with tumor grade I and miR-126 positivity was similar to that for grade II, and this was significantly higher than for grade III and IV $(P=0.002)$ There was no significant association between miR-126 expression and patient age, sex, or tumor laterality (Table 2).

miR-126 Expression Level and Patient Survival

In the univariate analysis, patients with higher miR-126 expression exhibited a significant increase in both DFS (hazard ratio $\mathrm{HR}=0.30,95 \% \mathrm{CI}=0.18$ to 0.50 , $P<0.001)$ and $\mathrm{OS}(\mathrm{HR}=0.40,95 \% \mathrm{CI}=0.19$ to 0.86 , $P=0.019)$. The same trend toward better prognosis was observed in the multivariate analysis for both DFS $(\mathrm{HR}=0.58,95 \% \mathrm{CI}=0.32$ to 1.04$)$ and $\mathrm{OS}(\mathrm{HR}=0.78$, $95 \% \mathrm{CI}=0.32$ to 1.87$)$, although the trend did not reach statistical significance $(P=0.066$ and $P=0.57$, respectively) (Table 3). Assessing miR-126 as a binary variable, Kaplan-Meier survival curves indicated that miR-126 positivity was associated with significantly longer DFS $(P<0.001)$ and $\mathrm{OS}(P=0.015)$ (Figure $2, \mathrm{~A}$ and $\mathrm{B})$.

We further stratified patients according to tumor size. For larger tumors $(>4 \mathrm{~cm})$, miR-126 ${ }^{+}$patient had significantly longer DFS $(P<0.001)$ and $\mathrm{OS}(P=0.039)$ (Figure $2, \mathrm{C}$ and D). For smaller tumors $(\leq 4 \mathrm{~cm})$, miR-126 expression was associated with increased DFS, although the association was not statistically significant $(P=0.23)$ (data not shown).

\section{Validation of the Prognostic Significance of miR-126}

We further validated our results in silico on an independent data set of 481 ccRCC cases from TCGA. Kaplan-Meier curves showed that patients with miR-126 overexpression had significantly longer OS compared with those with lower miR-126 expression ( $\mathrm{HR}=0.59, P=0.0009$ ) (Supplemental Figure S1C). In the same data set, miR-126 expression was significantly down-regulated in tumor stage III/IV, compared with stage $\mathrm{I} / \mathrm{II}(P=0.0056)$. It was also significantly higher in tumor stage I compared with stages II, III and IV $(P=0.0009$, 0.0129 , and 0.0002, respectively) (data not shown).

In the subset of patients with stage I tumors from the same data set $(n=198)$, increased expression of miR-126 was associated with longer OS, although the association was not statistically significant $(\mathrm{HR}=0.53, P=0.17)$ (Supplemental Figure S1D).

We also analyzed the subgroup of patients with larger tumors $(>4 \mathrm{~cm})(n=268)$, and similar results were obtained. In this subgroup, patients with increased miR-126 expression had significantly longer $\mathrm{OS}(\mathrm{HR}=0.48, P=0.0035)$ (Figure 3A). In the subgroup of 108 patients with smaller 

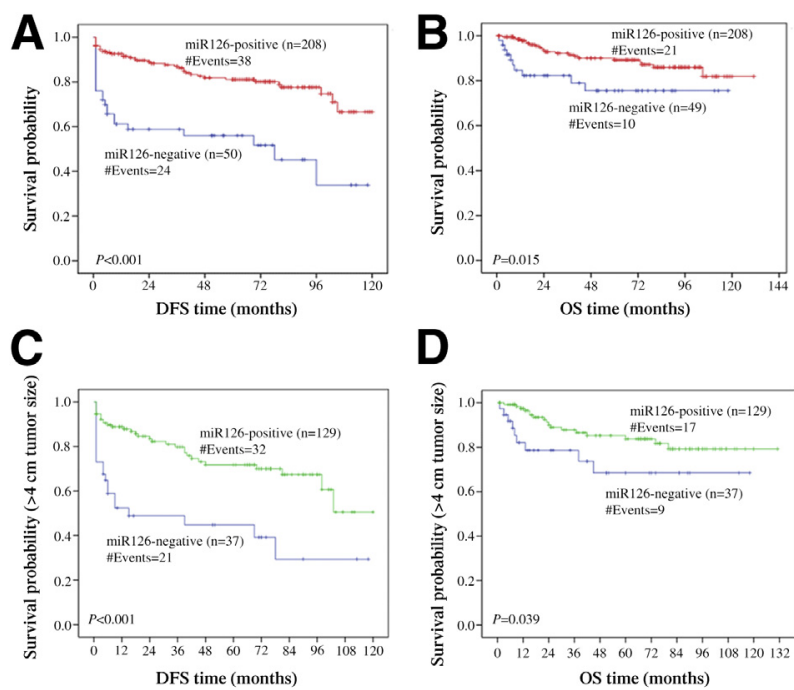

Figure 2 Kaplan-Meier curves for DFS and OS of cCRCC patients with miR- $126^{+}$and miR-126 tumors. Patients were classified as miR- $126^{+}$or miR- $126^{-}$using a statistically determined cutoff. miR $-126^{+}$patients had significantly longer DFS (A) and OS (B), compared with miR-126- patients. In the subgroup with larger tumors $(>4 \mathrm{~cm}), \operatorname{miR}-126^{+}$patients had significantly longer DFS (C) and OS (D), compared with miR-126- patients. DFS, disease-free survival; $0 S$, overall survival.

tumors $(\leq 4 \mathrm{~cm})$, higher miR-126 expression was also associated with longer OS, although the association was not statistically significant $(\mathrm{HR}=0.49, P=0.16$ ) (data not shown). These results are in accord with our PCR-based tissue analysis.

\section{miR-126 Targets Critical Pathways and Key Molecules Involved in Tumor Progression}

Our bioinformatics analysis showed that miR-126 targets key molecules and pathways involved in tumor progression. Target prediction analysis identified a number of molecules as predicted targets for miR-126, including SPRED1, IGF1R, BCL2, CRK, CCNE2, and PIK3R2. Pathway analysis showed that miR-126 targets critical tumorigenesis pathways, including HIF-1, VEGF, mTOR, and PI3K-Akt signaling pathways (Supplemental Table S2).

An interesting observation is that miR-126 is intronic, located within the EGFL7 gene. Interestingly, EGFL7 is also a predicted target of miR-126. To examine the relationship between miR-126 and expression of its host gene, we analyzed EGFL7 expression in $481 \mathrm{ccRCC}$ patients and its correlation with OS. Lower expression of EGFL7 was associated with longer $\mathrm{OS}(\mathrm{HR}=1.45, P=0.027)$ (Supplemental Figure S1E). We confirmed an inverse correlation between the miRNA and its targets, and then explored the potential utility of miR-126 targets as prognostic markers. We analyzed the expression of three additional targets (PIK3CD, VEGFA, and PIK3R2) in relation to survival in the same TCGA set of patients. Lower expression of each of these molecules was associated with longer survival
$\left(\mathrm{HR}=3.58, P=2.9 \times 10^{-06}, \mathrm{HR}=3.35, P=0.00099\right.$, and $\mathrm{HR}=3.02, P=0.0015$, respectively) (Figure 3, B and $\mathrm{C}$ and Supplemental Figure S1F).

\section{miR-126 0verexpression Decreases Cellular Migration Rate}

We first checked the endogenous expression levels of miR126 in different RCC cell lines. The 786-O and ACHN cell lines had very low endogenous expression levels. The cells were then transfected with miR-126. Successful transfection was confirmed by RT-qPCR. Expression levels remained significantly high for 3 days. We then investigated the effect of miR-126 on cellular migration, using a wound-healing assay in 786-O cells transfected with miR-126. miR-126 overexpression resulted in significant reduction in the rate of cell migration, compared with untransfected cells $(P=0.0379)$, cells transfected with transfection reagent only $(P=0.0379)$, and the scrambled RNA negative control $(P=0.0499)$ (Figure $4, \mathrm{~A}$ and $\mathrm{B})$. Similar results were obtained for ACHN cells (data not shown).

\section{miR-126 0verexpression Reduces Cellular Proliferation}

We examined the effect of miR-126 on kidney cancer cellular proliferation. 786-O and ACHN cells were transfected with miR-126, and appropriate controls were used as described above. In 786-O cells, miR-126 transfection significantly decreased cellular proliferation, compared with untransfected cells $(P=0.0151)$, cells transfected with transfection agent only $(P=0.0035)$, or scrambled miRNA $(P=0.0075)$ (Figure 4C). Similar results were obtained for ACHN cells (data not shown).

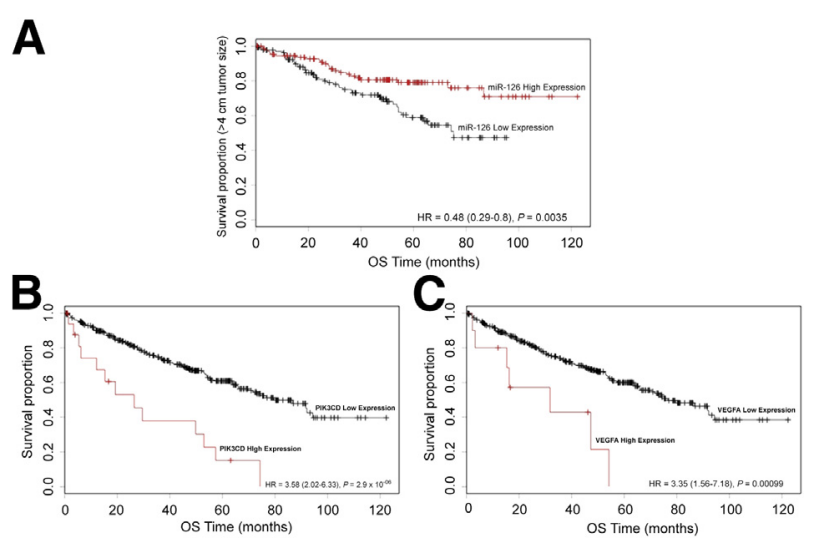

Figure 3 A: The prognostic significance of miR-126 expression in ccRCC patients with larger tumors $(>4 \mathrm{~cm})$. We correlated the expression level of miR-126 and OS in a subgroup of ccRCC patients with larger tumors $(>4 \mathrm{~cm})$. Higher expression of miR-126 was significantly associated with longer $0 \mathrm{~S}$. These results are in agreement with our CCRCC PCR-based tissue analysis. B and C: The expression of miR-126-predicted targets negatively correlated with survival. PIK3CD and VEGFA expression levels in $481 \mathrm{cCRCC}$ patients were obtained from TCGA and correlated with patient OS. Lower expression of each of these molecules was associated with longer survival. HR, hazard ratio (95\% CI); TCGA, The Cancer Genome Atlas. 

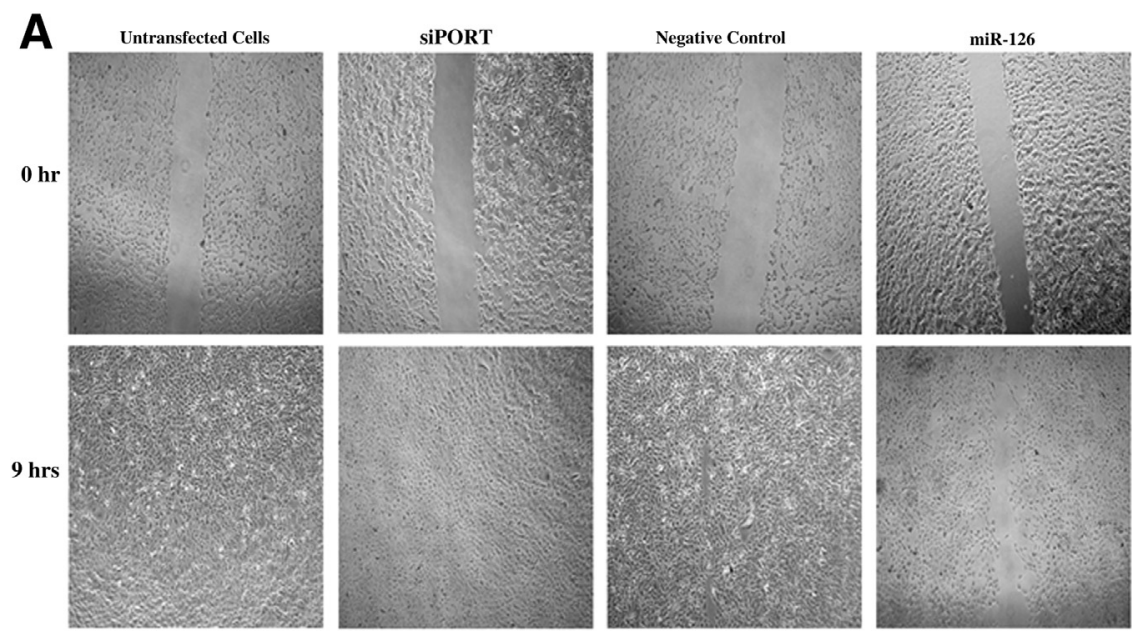

B

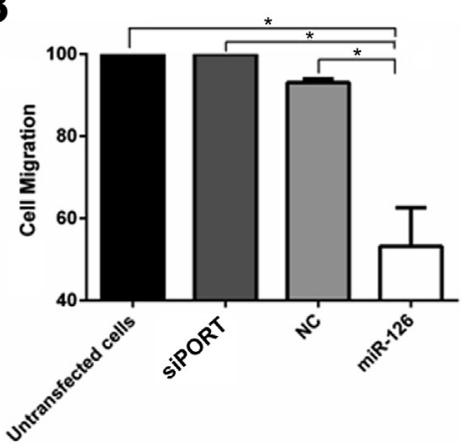

C

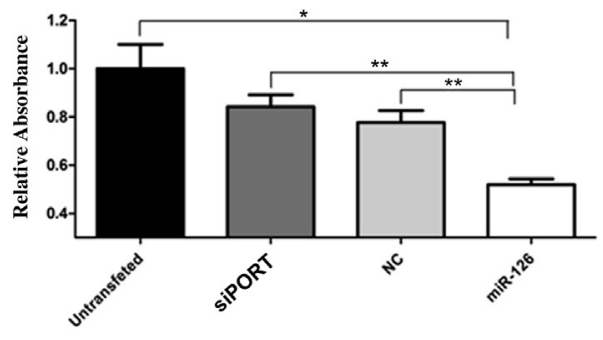

Figure 4 miR-126 overexpression reduces cellular migration and proliferation. A: Representative photomicrographs show the effect of miR126 overexpression on the migration rate of the 786-0 RCC cell line at the time of wounding (0 hour) and after 9 hours. Overexpression of miR126 significantly decreases the rate of cell migration, with incomplete wound closure after 9 hours, compared with controls. B: Effect of miR-126 on cellular migration, expressed as: \% cell-covered area (100 - \% cell-free area). C: Overexpression of miR-126 has a negative effect on cellular proliferation. 786-0 RCC cells transfected with miR-126 show significantly reduced cellular proliferation, compared with control cells. Similar results were obtained for ACHN RCC cells. $n=3$. Data are expressed as means \pm SEM. ${ }^{*} P<0.05,{ }^{* *} P<0.01$ versus control. NC, negative control; siPORT, transfection agent.

\section{miR-126 Regulates Apoptosis Signaling Pathway}

To further validate miR-126-target interactions and to validate the effect on molecular pathways, we chose the apoptosis pathway for experimental validation. 786-O cells were transfected with miR-126. The experiment was performed in triplicate. miR-126 overexpression resulted in significant reduction of the expression levels of a number of its targets that represent key molecules controlling apoptosis signaling pathway, including BCL2 $(P=0.04)$, PIK3R2 $(P=4.12 \times$ $\left.10^{-7}\right)$, PIK3CD $\left(P=1.53 \times 10^{-7}\right)$, IGF1R $(P=0.001)$, and VEGFA $(P=0.01)$ (Figure 5$)$. We further examined the overall effect of miR-126 overexpression on the apoptosis pathway using PCR array analysis. miR-126 overexpression resulted in significant alteration of apoptosis $(P=0.0299)$ (data not shown).

\section{miR-126 Expression in Different Subtypes of Kidney Cancer}

We compared miR-126 expression in normal kidney tissue, benign oncocytoma, and common RCC subtypes including clear cell, papillary, and chromophobe RCC. miR-126 was significantly up-regulated in ccRCC versus normal kidney tissue $(P<0.0001)$, papillary RCC $(P<0.0001)$, chromophobe RCC $(P<0.0001)$, and oncocytoma $(P=0.0075)$. miR-126 expression was lowest in papillary RCC, and expression levels was similar to normal in both oncocytoma and chromophobe RCC (Figure 6).

\section{miR-126 Is Conserved among Species}

We performed sequence comparison of miR-126 among species by using the University of California Santa Cruz Genome Browser. miR-126 was highly conserved among vertebrate 46 species (data not shown), which might indicate important functions of miR-126 that are highly conserved

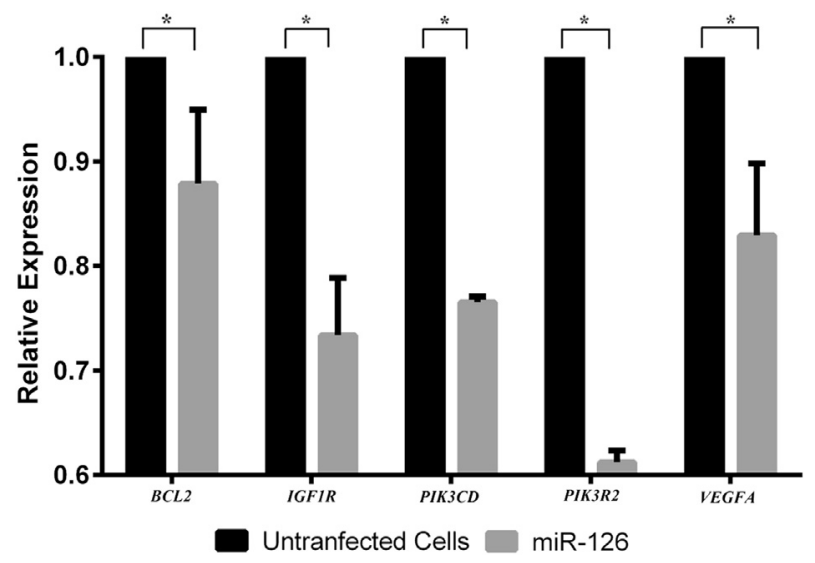

Figure 5 Validation of miR-126 targets. miR-126 decreases the expression levels of key molecules involved in apoptosis, including BCL2, IGF1R, PIK3CD, PIK3R2, and VEGFA. $n=3$. Data are expressed as means \pm SEM. ${ }^{*} P<0.05$. 


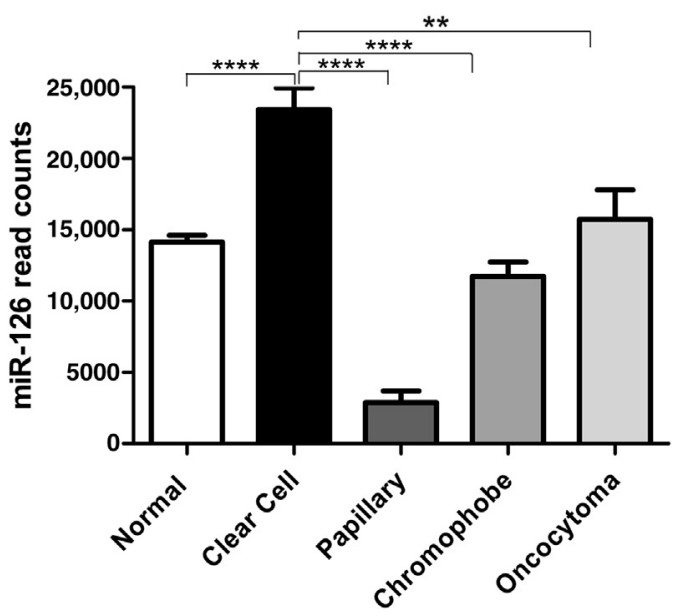

Figure 6 miR-126 expression in normal kidney tissue and RCC subtypes. We compared miR-126 expression between normal kidney, oncocytoma, and common RCC subtypes. cCRCC shows the highest expression level of miR126 , and papillary RCC shows the lowest expression. In both oncocytoma and chromophobe RCC, expression of miR-126 is similar to that of normal tissue. Data are expressed as means \pm SEM. $n=20$ per group. ${ }^{* *} P<0.01$, $* * * * P<0.0001$

among species and have a critical role in development and differentiation.

\section{Discussion}

Recently, miRNAs have attracted attention as promising diagnostic, prognostic, and predictive biomarkers in different cancers. In the present study, we demonstrated that miR-126 is a potential prognostic marker in ccRCC. Our results show that miR-126 overexpression is significantly associated with longer DFS and OS. These findings were confirmed in an independent data set from TCGA, and are in keeping with recent reports. miR-126 is significantly correlated with relapse-free survival after nephrectomy in nonmetastatic RCC patients, ${ }^{14}$ and the combination of miR-21 and miR-126 is associated with longer survival in ccRCC patients. ${ }^{35}$ Lower expression of miR-126 is associated with poor survival in malignant mesothelioma, ${ }^{36}$ and miR-126 down-regulation is associated with increased microvessel density and poor survival in non-small cell lung cancer. ${ }^{37,38}$ miR-126 downregulation is also associated with hepatocellular carcinoma recurrence. $^{39}$ High expression of miR-151-3p and low expression of miR-126 can predict longer OS after resection for cholangiocarcinoma. ${ }^{40}$ Similarly, increased expression of plasma miR-155 and reduced miR-126 expression correlate with poor prognosis. ${ }^{41} \mathrm{Li}$ et al ${ }^{42}$ identified a seven-member miRNA signature (including miR-126) predictive of clinical outcome in gastric cancer.

We have previously demonstrated that miR-126 expression is down-regulated in metastatic versus primary ccRCC tumors. ${ }^{15,16}$ In the present study, we validated these results in a larger set of patients with metastatic and primary ccRCC.
Our data showed that miR-126 is significantly lower in tumors of higher stage, and this was validated in the independent data set from TCGA. Lower expression of miR-126 was also shown to be associated with stage IV in non-small cell lung cancer and colorectal cancer. ${ }^{43,44}$ Similarly, we observed miR-126 down-regulation in tumor grades III/IV, compared with grades I/II. Lower expression of miR-126 was reported to be associated with high tumor grade in prostate cancer. ${ }^{22}$ When we further analyzed the stage I subgroup of patients, we found that miR-126 overexpression was associated with longer OS. Although the association was not statistically significant, the finding provides preliminary evidence for miR-126 as a promising prognostic marker in the early stage of RCC.

Recently, it was reported that tumor diameter at the time of diagnosis cannot predict tumor prognosis. ${ }^{45}$ Our present results show that miR-126 expression can stratify patients with larger tumors $(>4 \mathrm{~cm})$ into two distinct prognostic subgroups, with miR-126 expression significantly associated with longer survival. These results were confirmed in our validation set.

The role of miR-126 in carcinogenesis still needs to be elucidated. miR-126 is down-regulated in lung, esophageal, and prostate cancers, ${ }^{20,22,46}$ and a tumor suppressor role has been reported in some cancers. ${ }^{27,30}$ On the other hand, the same miRNA is up-regulated in patients with urothelial cancer, ${ }^{47}$ and an oncogenic effect of miR-126 has been suggested for gastric cancer. ${ }^{48}$ In RCC, our findings indicate that miR-126 is up-regulated, compared with normal kidney. These results were validated in an independent set from TCGA, and our analysis is in accord with previous reports for ccRCC. ${ }^{49,50}$

Our target prediction and our pathway analysis and literature search showed that miR-126 can target key molecules and critical pathways involved in ccRCC tumor development and progression, including the HIF-1, VEGF, mTOR, and PI3K-Akt signaling pathways. ${ }^{51}$ Our findings showed that miR-126 is predicted to target SPRED1 which has been reported to regulate Ras-Raf-ERK and VEGF signaling pathway. ${ }^{52-54}$ miR-126 targets VEGFA and PIK3R2 in breast cancer. ${ }^{55}$ In addition, miR-126 targets VEGFA in oral and colorectal cancers. ${ }^{26,56}$ VEGFA is not a direct target of miR126 in endothelial cells; instead, miR-126 increases VEGFA activity by targeting SPRED $1 .{ }^{57}$

Our analysis showed that IGF1R and BCL2 are also predicted targets for miR-126. IGF1R was shown to be associated with poor survival in RCC ${ }^{58}$ and recently it was shown that targeting IGF1R in combination with mTOR inhibitors decreases cellular proliferation in RCC. ${ }^{59}$ The antiapoptotic BCL2 is up-regulated in metastatic versus primary ccRCC. ${ }^{60}$

miR-126 lies within intron 7 of EGFL7. Although previous reports showed that miR-126 can be coregulated with its EGFL7 host gene, ${ }^{61}$ our results show an opposite expression pattern. Our target prediction identified EGFL7 as a predicted target for miR-126, which can explain the finding that higher expression of miR-126 was associated 
with longer survival but that higher expression of EGFL7 was associated with shorter survival. Thus, the correlation between miR-126 and its host gene can be tissue-specific. Our findings are in accord with report that miR-126 targets $E G F L 7$ in lung cancer. ${ }^{62}$ Some intronic miRNAs have the ability to function both ways; that is, they can either be coexpressed with their host gene or target it. ${ }^{63}$

We compared miR-126 expression in the different RCC subtypes. ccRCC showed the highest miR-126 expression, and papillary RCC showed the lowest expression. These findings support previous studies demonstrating that miR126 is a promising molecular classifier, one that can clearly distinguish between ccRCC and papillary RCC. 5,64,65

In conclusion, we have demonstrated that miR-126 is down-regulated in metastatic versus primary ccRCC. We have also shown that miR-126 expression can be used to distinguish between ccRCC and papillary RCC subtypes. In our survival analysis, higher expression of miR-126 was associated with longer survival. miR-126 also had prognostic significance in the subgroup of patients with larger tumors $(>4 \mathrm{~cm})$. We validated our results on a large independent set of patient data collected from the Cancer Genome Atlas. Finally, we have identified a number of miR126-predicted targets and pathways that are involved in RCC pathogenesis.

\section{Supplemental Data}

Supplemental material for this article can be found at http://dx.doi.org/10.1016/j.ajpath.2014.11.017.

\section{References}

1. US Burden of Disease Collaborators: The state of US health, 1990-2010: burden of diseases, injuries, and risk factors. JAMA 2013, 310:591-608

2. Chow WH, Dong LM, Devesa SS: Epidemiology and risk factors for kidney cancer. Nat Rev Urol 2010, 7:245-257

3. Nerich V, Hugues M, Paillard MJ, Borowski L, Nai T, Stein U, Nguyen Tan HT, Montcuquet P, Maurina T, Mouillet G, Kleinclauss F, Pivot X, Limat S, Thiery-Vuillemin A: Clinical impact of targeted therapies in patients with metastatic clear-cell renal cell carcinoma. Onco Targets Ther 2014, 7:365-374

4. Wang L, Williamson SR, Wang M, Davidson DD, Zhang S, Baldridge LA, Du X, Cheng L: Molecular subtyping of metastatic renal cell carcinoma: implications for targeted therapy. Mol Cancer $2014,13: 39$

5. Youssef YM, White NM, Grigull J, Krizova A, Samy C, MejiaGuerrero S, Evans A, Yousef GM: Accurate molecular classification of kidney cancer subtypes using microRNA signature. Eur Urol 2011, 59: $721-730$

6. Delahunt B, Srigley JR, Montironi R, Egevad L: Advances in renal neoplasia: recommendations from the 2012 International Society of Urological Pathology Consensus Conference. Urology 2014, 83: 969-974

7. Kurban G, Gedye C, Morales C, Yousef GM, Almatar A, Jewett MA: Diagnosis and treatment of small renal masses: the role for molecular biology. Arch Esp Urol 2013, 66:505-516
8. Pahernik S, Ziegler S, Roos F, Melchior SW, Thuroff JW: Small renal tumors: correlation of clinical and pathological features with tumor size. J Urol 2007, 178:414-417

9. Turun S, Banghua L, Zheng S, Wei Q: Is tumor size a reliable predictor of histopathological characteristics of renal cell carcinoma? Urol Ann 2012, 4:24-28

10. Deng G, Sui G: Noncoding RNA in oncogenesis: a new era of identifying key players. Int J Mol Sci 2013, 14:18319-18349

11. White NM, Fatoohi E, Metias M, Jung K, Stephan C, Yousef GM: Metastamirs: a stepping stone towards improved cancer management. Nat Rev Clin Oncol 2011, 8:75-84

12. Faragalla H, Youssef YM, Scorilas A, Khalil B, White NM, MejiaGuerrero S, Khella H, Jewett MA, Evans A, Lichner Z, Bjarnason G, Sugar L, Attalah MI, Yousef GM: The clinical utility of miR-21 as a diagnostic and prognostic marker for renal cell carcinoma. J Mol Diagn 2012, 14:385-392

13. Jung M, Mollenkopf HJ, Grimm C, Wagner I, Albrecht M, Waller T, Pilarsky C, Johannsen M, Stephan C, Lehrach H, Nietfeld W, Rudel T, Jung K, Kristiansen G: MicroRNA profiling of clear cell renal cell cancer identifies a robust signature to define renal malignancy. J Cell Mol Med 2009, 13:3918-3928

14. Slaby O, Redova M, Poprach A, Nekvindova J, Iliev R, Radova L, Lakomy R, Svoboda M, Vyzula R: Identification of microRNAs associated with early relapse after nephrectomy in renal cell carcinoma patients. Genes Chromosomes Cancer 2012, 51:707-716

15. Khella HW, White NM, Faragalla H, Gabril M, Boazak M, Dorian D, Khalil B, Antonios H, Bao TT, Pasic MD, Honey RJ, Stewart R, Pace KT, Bjarnason GA, Jewett MA, Yousef GM: Exploring the role of miRNAs in renal cell carcinoma progression and metastasis through bioinformatic and experimental analyses. Tumour Biol 2012, $33: 131-140$

16. White NM, Khella HW, Grigull J, Adzovic S, Youssef YM, Honey RJ, Stewart R, Pace KT, Bjarnason GA, Jewett MA, Evans AJ, Gabril M, Yousef GM: miRNA profiling in metastatic renal cell carcinoma reveals a tumour-suppressor effect for miR-215. Br J Cancer 2011, 105:1741-1749

17. Zhang Y, Yang P, Sun T, Li D, Xu X, Rui Y, Li C, Chong M, Ibrahim T, Mercatali L, Amadori D, Lu X, Xie D, Li QJ, Wang XF: miR-126 and miR-126* repress recruitment of mesenchymal stem cells and inflammatory monocytes to inhibit breast cancer metastasis. Nat Cell Biol 2013, 15:284-294

18. Ebrahimi F, Gopalan V, Smith RA, Lam AK: miR-126 in human cancers: clinical roles and current perspectives. Exp Mol Pathol 2014, 96:98-107

19. Hansen TF, Christensen R, Andersen RF, Sorensen FB, Johnsson A, Jakobsen A: MicroRNA-126 and epidermal growth factor-like domain 7-an angiogenic couple of importance in metastatic colorectal cancer. Results from the Nordic ACT trial. Br J Cancer 2013, 109:1243-1251

20. Liu SG, Qin XG, Zhao BS, Qi B, Yao WJ, Wang TY, Li HC, Wu XN: Differential expression of miRNAs in esophageal cancer tissue. Oncol Lett 2013, 5:1639-1642

21. Markou A, Sourvinou I, Vorkas PA, Yousef GM, Lianidou E: Clinical evaluation of microRNA expression profiling in non small cell lung cancer. Lung Cancer 2013, 81:388-396

22. Walter BA, Valera VA, Pinto PA, Merino MJ: Comprehensive microRNA profiling of prostate cancer. J Cancer 2013, 4: $350-357$

23. Felli N, Felicetti F, Lustri AM, Errico MC, Bottero L, Cannistraci A, De FA, Petrini M, Pedini F, Biffoni M, Alvino E, Negrini M, Ferracin M, Mattia G, Care A: miR-126\&126* restored expressions play a tumor suppressor role by directly regulating ADAM9 and MMP7 in melanoma. PLoS One 2013, 8:e56824

24. Agudo J, Ruzo A, Tung N, Salmon H, Leboeuf M, Hashimoto D, Becker C, Garrett-Sinha LA, Baccarini A, Merad M, Brown BD: The miR-126-VEGFR2 axis controls the innate response to pathogenassociated nucleic acids. Nat Immunol 2014, 15:54-62 
25. Huang TH, Chu TY: Repression of miR-126 and upregulation of adrenomedullin in the stromal endothelium by cancer-stromal cross talks confers angiogenesis of cervical cancer. Oncogene 2014, 33: 3636-3647

26. Sasahira T, Kurihara M, Bhawal UK, Ueda N, Shimomoto T, Yamamoto K, Kirita T, Kuniyasu H: Downregulation of miR-126 induces angiogenesis and lymphangiogenesis by activation of VEGF-A in oral cancer. Br J Cancer 2012, 107:700-706

27. Li Z, Li N, Wu M, Li X, Luo Z, Wang X: Expression of miR-126 suppresses migration and invasion of colon cancer cells by targeting CXCR4. Mol Cell Biochem 2013, 381:233-242

28. Li N, Tang A, Huang S, Li Z, Li X, Shen S, Ma J, Wang X: miR-126 suppresses colon cancer cell proliferation and invasion via inhibiting RhoA/ROCK signaling pathway. Mol Cell Biochem 2013, 380: 107-119

29. Banerjee N, Kim H, Talcott S, Mertens-Talcott S: Pomegranate polyphenolics suppressed azoxymethane-induced colorectal aberrant crypt foci and inflammation: possible role of miR-126/VCAM-1 and miR-126/PI3K/AKT/mTOR. Carcinogenesis 2013, 34: $2814-2822$

30. Xu JQ, Liu P, Si MJ, Ding XY: MicroRNA-126 inhibits osteosarcoma cells proliferation by targeting Sirt1. Tumour Biol 2013, 34: $3871-3877$

31. Tumours of the kidney. Pathology and Genetics of Tumours of the Urinary System and Male Genital Organs. Edited by Eble JN, Sauter G, Epstein JI, Sesterhenn I. World Health Organization Classification of Tumours. Lyon, IARCPress, 2004, pp 12-87

32. White NM, Chow TF, Mejia-Guerrero S, Diamandis M, Rofael Y, Faragalla H, Mankaruous M, Gabril M, Girgis A, Yousef GM: Three dysregulated miRNAs control kallikrein 10 expression and cell proliferation in ovarian cancer. $\mathrm{Br} \mathrm{J}$ Cancer 2010, 102: $1244-1253$

33. White NM, Bui A, Mejia-Guerrero S, Chao J, Soosaipillai A, Youssef Y, Mankaruos M, Honey RJ, Stewart R, Pace KT, Sugar L, Diamandis EP, Doré J, Yousef GM: Dysregulation of kallikreinrelated peptidases in renal cell carcinoma: potential targets of miRNAs. Biol Chem 2010, 391:411-423

34. Xiao F, Zuo Z, Cai G, Kang S, Gao X, Li T: miRecords: an integrated resource for microRNA-target interactions. Nucleic Acids Res 2009, 37(Database issue):D105-D110

35. Vergho D, Kneitz S, Rosenwald A, Scherer C, Spahn M, Burger M, Riedmiller H, Kneitz B: Combination of expression levels of miR-21 and miR-126 is associated with cancer-specific survival in clear-cell renal cell carcinoma. BMC Cancer 2014, 14:25

36. Tomasetti M, Staffolani S, Nocchi L, Neuzil J, Strafella E, Manzella N, Mariotti L, Bracci M, Valentino M, Amati M, Santarelli L: Clinical significance of circulating miR-126 quantification in malignant mesothelioma patients. Clin Biochem 2012, 45: $575-581$

37. Jusufović E, Rijavec M, Keser D, Korošec P, Sodja E, Iljazović E, Radojević Z, Košnik M: let-7b and miR-126 are down-regulated in tumor tissue and correlate with microvessel density and survival outcomes in non-small-cell lung cancer. PLoS One 2012, 7: e45577

38. Sanfiorenzo C, Ilie MI, Belaid A, Barlési F, Mouroux J, Marquette CH, Brest P, Hofman P: Two panels of plasma microRNAs as non-invasive biomarkers for prediction of recurrence in resectable NSCLC. PLoS One 2013, 8:e54596

39. Chen H, Miao R, Fan J, Han Z, Wu J, Qiu G, Tang H, Peng Z: Decreased expression of miR-126 correlates with metastatic recurrence of hepatocellular carcinoma. Clin Exp Metastasis 2013, 30: 651-658

40. McNally ME, Collins A, Wojcik SE, Liu J, Henry JC, Jiang J, Schmittgen T, Bloomston M: Concomitant dysregulation of microRNAs miR-151-3p and miR-126 correlates with improved survival in resected cholangiocarcinoma. HPB (Oxford) 2013, 15: 260-264
41. Ishihara K, Sasaki D, Tsuruda K, Inokuchi N, Nagai K, Hasegawa H, Yanagihara K, Kamihira S: Impact of miR-155 and miR-126 as novel biomarkers on the assessment of disease progression and prognosis in adult T-cell leukemia. Cancer Epidemiol 2012, 36:560-565

42. Li X, Zhang Y, Zhang Y, Ding J, Wu K, Fan D: Survival prediction of gastric cancer by a seven-microRNA signature. Gut 2010, 59: $579-585$

43. Lin Q, Mao W, Shu Y, Lin F, Liu S, Shen H, Gao W, Li S, Shen D: A cluster of specified microRNAs in peripheral blood as biomarkers for metastatic non-small-cell lung cancer by stem-loop RT-PCR. J Cancer Res Clin Oncol 2012, 138:85-93

44. Liu Y, Zhou Y, Feng X, Yang P, Yang J, An P, Wang H, Ye S, Yu C, He Y, Luo H: Low expression of microRNA-126 is associated with poor prognosis in colorectal cancer. Genes Chromosomes Cancer 2014, 53:358-365

45. Organ M, Jewett M, Basiuk J, Morash C, Pautler S, Siemens DR, Tanguay S, Gleave M, Drachenberg D, Chow R, Chin J, Evans A, Fleshner N, Gallie B, Haider M, Kachura J, Finelli A, Rendon RA: Growth kinetics of small renal masses: a prospective analysis from the Renal Cell Carcinoma Consortium of Canada. Can Urol Assoc J 2014, 8:24-27

46. Guan P, Yin Z, Li X, Wu W, Zhou B: Meta-analysis of human lung cancer microRNA expression profiling studies comparing cancer tissues with normal tissues. J Exp Clin Cancer Res 2012, 31:54

47. Snowdon J, Boag S, Feilotter H, Izard J, Siemens DR: A pilot study of urinary microRNA as a biomarker for urothelial cancer. Can Urol Assoc J 2012:1-5

48. Otsubo T, Akiyama Y, Hashimoto Y, Shimada S, Goto K, Yuasa Y: MicroRNA-126 inhibits SOX2 expression and contributes to gastric carcinogenesis. PLoS One 2011, 6:e16617

49. Chow TF, Youssef YM, Lianidou E, Romaschin AD, Honey RJ, Stewart R, Pace KT, Yousef GM: Differential expression profiling of microRNAs and their potential involvement in renal cell carcinoma pathogenesis. Clin Biochem 2010, 43:150-158

50. White NM, Bao TT, Grigull J, Youssef YM, Girgis A, Diamandis M, Fatoohi E, Metias M, Honey RJ, Stewart R, Pace KT, Bjarnason GA, Yousef GM: miRNA profiling for clear cell renal cell carcinoma: biomarker discovery and identification of potential controls and consequences of miRNA dysregulation. J Urol 2011, 186:1077-1083

51. Lichner Z, Mejia-Guerrero S, Ignacak M, Krizova A, Bao TT, Girgis AH, Youssef YM, Yousef GM: Pleiotropic action of renal cell carcinoma-dysregulated miRNAs on hypoxia-related signaling pathways. Am J Pathol 2012, 180:1675-1687

52. Anand S, Cheresh DA: Emerging role of micro-RNAs in the regulation of angiogenesis. Genes Cancer 2011, 2:1134-1138

53. Nicoli S, Standley C, Walker P, Hurlstone A, Fogarty KE, Lawson ND: MicroRNA-mediated integration of haemodynamics and Vegf signalling during angiogenesis [Erratum appeared in Nature 2010, 467:356]. Nature 2010, 464:1196-1200

54. Zhuang L, Villiger P, Trueb B: Interaction of the receptor FGFRL1 with the negative regulator Spred1. Cell Signal 2011, 23: $1496-1504$

55. Zhu N, Zhang D, Xie H, Zhou Z, Chen H, Hu T, Bai Y, Shen Y, Yuan W, Jing Q, Qin Y: Endothelial-specific intronderived miR-126 is down-regulated in human breast cancer and targets both VEGFA and PIK3R2. Mol Cell Biochem 2011, 351:157-164

56. Zhang Y, Wang X, Xu B, Wang B, Wang Z, Liang Y, Zhou J, Hu J, Jiang B: Epigenetic silencing of miR-126 contributes to tumor invasion and angiogenesis in colorectal cancer. Oncol Rep 2013, 30: 1976-1984

57. Wang S, Aurora AB, Johnson BA, Qi X, McAnally J, Hill JA, Richardson JA, Bassel-Duby R, Olson EN: The endothelial-specific microRNA miR-126 governs vascular integrity and angiogenesis. Dev Cell 2008, 15:261-271 
58. Parker AS, Cheville JC, Blute ML, Igel T, Lohse CM, Cerhan JR: Pathologic T1 clear cell renal cell carcinoma: insulin-like growth factor-I receptor expression and disease-specific survival. Cancer 2004, 100:2577-2582

59. Cardillo TM, Trisal P, Arrojo R, Goldenberg DM, Chang CH: Targeting both IGF-1R and mTOR synergistically inhibits growth of renal cell carcinoma in vitro. BMC Cancer 2013, 13:170

60. Lee CT, Genega EM, Hutchinson B, Fearn PA, Kattan MW, Russo P, Reuter VE: Conventional (clear cell) renal carcinoma metastases have greater bcl-2 expression than high-risk primary tumors. Urol Oncol 2003, 21:179-184

61. Saito Y, Friedman JM, Chihara Y, Egger G, Chuang JC, Liang G: Epigenetic therapy upregulates the tumor suppressor microRNA-126 and its host gene EGFL7 in human cancer cells. Biochem Biophys Res Commun 2009, 379:726-731
62. Sun Y, Bai Y, Zhang F, Wang Y, Guo Y, Guo L: miR-126 inhibits non-small cell lung cancer cells proliferation by targeting EGFL7. Biochem Biophys Res Commun 2010, 391:1483-1489

63. Gao X, Qiao Y, Han D, Zhang Y, Ma N: Enemy or partner: relationship between intronic micrornas and their host genes. IUBMB Life 2012, 64:835-840

64. Fridman E, Dotan Z, Barshack I, David MB, Dov A, Tabak S, Zion O, Benjamin S, Benjamin H, Kuker H, Avivi C, Rosenblatt K, Polak-Charcon S, Ramon J, Rosenfeld N, Spector Y: Accurate molecular classification of renal tumors using microRNA expression. J Mol Diagn 2010, 12:687-696

65. Powers MP, Alvarez K, Kim HJ, Monzon FA: Molecular classification of adult renal epithelial neoplasms using microRNA expression and virtual karyotyping. Diagn Mol Pathol 2011, 20: $63-70$ 